\title{
Gastrointestinal perforation due to vasculitis at primary diagnosis of eosinophilic granulomatosis with polyangiitis (EGPA) despite a high dose glucocorticosteroids treatment
}

\author{
Gunter Assmann ${ }^{1 *}$, Marc Molinger ${ }^{1}$, Michael Pfreundschuh¹, Rainer Bohle ${ }^{2}$ and Vincent Zimmer ${ }^{3}$
}

\begin{abstract}
Background: Eosinophilic granulomatosis with polyangiitis (EGPA) belongs to the systemic ANCA-associated vasculitides which may develop life-threatening major organ involvement, such as eosinophilic pulmonary infiltration, neuropathy, acute nephritis, myocarditis, and gastrointestinal (GI) tract involvement. Here, two cases of EGPA are presented developing perforation of the bowel at primary diagnosis after 7 respectively 10 days of initiation of high-dose glucocorticosteroides (GC) therapy.

Findings: Two male patients, aged 32 (case 1) and 36 years (case 2), were admitted to the hospital with the symptoms of dyspnea, fatigue, fever, and chest pain. The patients completed the previously published revised international Chapel Hill nomenclature of EGPA. The two patients (case 1 and 2) developed acute abdominal pain after 7 (case 1) and ten days (case 2) on GC treatment. Computed tomography followed by surgery detected acute perforation of the small intestine (middle part of jejunum, case 1) and colon transversum (case 2). The resected specimens disclosed bowel perforation with severe transmural inflammation, edema, hemorrhage and vasculitis typically of EGPA. On the first post-operative day, therapy with cyclophosphamide (according to the Austin protocol) with a dosage of $750 \mathrm{mg} / \mathrm{qm}$ every 3 weeks (for 8 cycles) was initiated with good response within three months of treatment.
\end{abstract}

Conclusion: The course of disease of the two presented EGPA patients suggest that very early initiation of intensified immunosuppressive treatment, preferentially with cyclophophomide or B cell depletion strategies, needs to be considered to avoid life-threatening complications of Gl involvement.

Keywords: Churg strauss; ANCA; Eosinophilic granulomatosis with polyangiitis; EGPA; Vasculitis; Gastrointestinal; Perforation

\section{Introduction}

Eosinophilic granulomatosis with polyangiitis (EGPA) belongs to the systemic vasculitides which may develop life-threatening major organ involvement Any type of vasculitis has the potential to cause local or diffuse pathological changes in the gastrointestinal (GI) tract based on the inflammation of vessel walls, followed by alterations of the blood flow and ischemic damage to the dependent

\footnotetext{
* Correspondence: gunter.assmann@uks.eu

'University Medical School of Saarland, Rheumatology and Oncology,

Kirrberger Strasse 1, D-66421 Homburg, Saar, Germany

Full list of author information is available at the end of the article
}

organ (Çileda» et al. 2012; Singh et al. 2009; Venditti et al. 2011). Intestinal manifestations have to be considered more common in other vasculitis disease, such as polyarteriitis nodosa, however, it seems to occur as severe manifestation of EGPA (Nakamura et al. 2002). Several case reports have been published with EGPA and GI tract involvement. Venditti et al. have previously published a case of EGPA vasculopathy with large bowel perforation, however, the patient has been under long-term treatment of GC during his course of disease (Venditti et al. 2011). Two cases of EGPA have been presented with intestinal vasculitis, one of them with perforation as initial 
presentation of EGPA after 20 days of admission in the hospital (Venditti et al. 2011; Murakami et al. 2004). Varbanova et al. have presented a similar EGPA case to the cases, which here have been presented, showing vasculitic intestine perforation within 3 weeks after diagnosis of EGPA (Varbanova et al. 2011). Guellivin et al. have published data from a relatively large cohort of 96 patients: during the course of EGPA 30\% of patients develop GI symptoms, such as abdominal pain, melena or hematemesis indicating intestinal vasulitic involvement (Guillevin et al. 1999). These data correspond to results from another cohort consisting in 150 EGPA patients previously published by (Moosig et al. 2013).

Here, two cases of EGPA are presented developing perforation of the bowel after initiation of high-dose GC therapy.

\section{Patients and methods}

The study was performed in compliance with the Helsinki Declaration, all patients have given the informed written consent to take part in the study, the agreement to perform the study was given by the Ethic Committee Saarland.

Two male patients, aged 32 (case 1) and 36 years (case 2 ), were admitted to the hospital with the symptoms of dyspnea, fatigue, fever, and chest pain (Table 1). Following diagnostic procedures, the patients complied with the previously published revised international Chapel Hill nomenclature of EGPA (Jennette et al. 2013), showing major organ involvement: myocarditis with heart failure NYHA II, mononeuritis multiplex L1 (only case 1), polyneuropathy (only case 2), bronchial asthma with eosinophile infiltrations, mild proteinuria (only case 1), and glomerular hematuria (only case 2). After bronchoalveolar lavage and biopsy of the skin (only case 1), treatment with GC at a dose of $1 \mathrm{mg}$ per $\mathrm{kg} /$ body weight was started. During GC administration the major organ manifestations were evaluated by completing diagnostic procedures, including biopsy of the suralis nerve (only case 1), endoscopy with multiple biopsies of the upper and lower intestine, MRI of the heart, and renal biopsy (only case 2).

\section{Results}

The two patients (case 1 and 2) developed acute abdominal pain after 7 (case 1) and ten days (case 2) on GC treatment and three and five days, respectively, after endoscopy. The performed biopsies during the endoscopy demonstrated vasculitis spots in both patients, but only in the upper intestine. Computed tomography followed by surgery detected an acute perforation of the small intestine (middle part of jejunum, case 1) and colon transversum (case 2). The resected specimen disclosed bowel perforation with severe transmural inflammation, edema, hemorrhage and vasculitis typical of EGPA. Figure 1 shows the endoscopic (figure A) and macroscopic view (figure B) of the resection specimen with multiple vasculitis induced necrotizing lesions with the corresponding histological preparation (figure C) after surgery (case 2). The colon perforation in case two was shown not to have occurred due to previously performed endoscopy biopsies. On the first post-operative day, therapy with cyclophosphamide due to major organ involvement

Table 1 Eosinophilic granulomatosis with polyangiitis patients' characteristics (case 1, 2)

\begin{tabular}{|c|c|c|c|}
\hline Characteristics & & Patient 1 & Patient 2 \\
\hline Time of diagnosis & & $4 / 2010$ & $1 / 2009$ \\
\hline Dosage of prednisolone ${ }^{a}$ & & $80 \mathrm{mg}$ & $90 \mathrm{mg}$ \\
\hline Days of GC treatment ${ }^{b}$ & & 7 & 10 \\
\hline \multicolumn{4}{|l|}{ Manifestations of EGPA } \\
\hline & Heart failure (NYHA stage) & $\|$ & $\|$ \\
\hline & Myocarditis ${ }^{c}$ & Present & Present \\
\hline & Neuropathy & Mononeuritis multiplex L1 & Polyneuropathy \\
\hline & Lung & Bronchial asthma & Asthma bronchiale \\
\hline & & Eosophile infiltration & \\
\hline & Kidney & Mild proteinuria (0.5 g/24 h) & Glomerular hematuria \\
\hline & Eosinophilic granulocytes ${ }^{d}$ & $5500 / \mu l$ & $4900 / \mu l$ \\
\hline IgE value & & Elevated & Elevated \\
\hline pANCA value & (Positive) $^{\mathrm{e}}$ & $12.8 \mathrm{U} / \mathrm{ml}^{\mathrm{f}}$ & $14.1 \mathrm{U} / \mathrm{ml}^{\mathrm{f}}$ \\
\hline
\end{tabular}

${ }^{a}$ intraveneous application once a day; ${ }^{b} \mathrm{GC}=$ glucocorticosteroides, till perforation followed by abdominal surgery; EGPA = eosinophilic granulomatosis with polyangiitis; ' histological proved by myocardial biopsy; ${ }^{d}$ counted in periphereal blood; ${ }^{e}$ pANCA = perinuclear pattern of antineutrophilic cytoplasmatic autoantibodies, tested by immunofluorescence test and by ELISA for myeloperoxidase autoantibodies (anti-MPO) ${ }^{\mathrm{f}}$ in U/ml; NYHA = New York Heart Association classification of heart failure. 

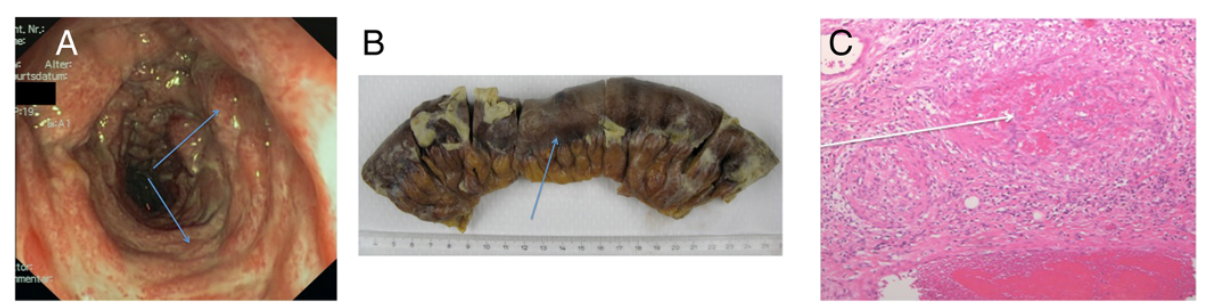

Figure 1 Colon transversum perforation of Churg Strauss patient (case 2) due to vasculitis. A: EGPA in case 2 and endoscopy in transverse colon with vasculitis lesions. B: EGPA in case 2 and macroscopic view of the resected transverse colon with vasculitis necrotizing lesions after surgery. C: EGPA in case 2 and histologic preparation of the resected transvere colon with eosinophilic infiltration and thrombotic vessel occlusion.

(according to the Austin protocol) with a dose of $750 \mathrm{mg} / \mathrm{qm}$ every 3 weeks (for 8 cycles) was initiated with good response within three months of treatment (case 1 and 2). Until the sixth month, the patients received azathioprine $2.5 \mathrm{mg} / \mathrm{kg}$ body weight without relapse of disease, and a reduction to a dose of $7.5 \mathrm{mg}$ prednisolone per day was implemented.

The good response of treatment was documented in reduction of eoasinophilic granulocytes lower than 2000/ $\mu \mathrm{l}$, normalization of the lung spirometry, complete remission of the myocarditis (measeared with MRI), and normalization of kidney function (with normal urine sediment test). However, both of them showed not ameliorated but persistent neuropathy, and patient one suffered from a persistent reduced ejection fraction of the heart after 12 weeks. The p-ANCA levels have not changed during the treatment period in both cases.

\section{Discussion}

We present two cases of GI perforation within two weeks after primary diagnosis of EGPA under treatment of highdose GC. The macroscopic and histologic preparation of the involved intestinal tract proved unconstrained inflammation as the most probable cause of perforation. After immediate postoperative initiation of intravenous cyclophosphamide treatment both cases have shown clinical remission during the following 12 weeks.

The treatment of EGPA with GI vasculitic involvement at primary diagnosis may not be sufficiently treated by $\mathrm{GC}$ alone to protect from life-threatening and very early occuring complications such as GI perforation. Murakami et al. has published a similar case of primary diagnosis of EGPA with GI perforation 20 days after admission to hospital, however, the GC dosage was lower (Murakami et al. 2004).

In general, GI involvement seems to be an indicator of poor prognosis in this disease entity and has been reported in an estimated $20-50 \%$ of patients (Guillevin et al. 1996; Hayami et al. 2012; Bourgarit et al. 2005). However, larger, more informative clinical study cohorts of EGPA patients to evaluate the true prognostic impact of GI vasculitis are currently not available. Nevertheless, previously published data from the French Vasculitis Study Group have evaluated the "five factors score" (FFS) to predict the risk of death due to EGPA (Bourgarit et al. 2005); the FFS score is widely used to assess the EGPA prognosis by giving one point for the involvement of GI, one point for involvement of the heart and the central nervous system, respectively, and one or two for the kidney manifestation (depending on serum creatinine and proteinuria) (Pagnoux et al. 2007; Guillevin et al. 2011; Vaglio et al. 2012). In general, Moosig et al. has demonstrated the probable benefit of immunosuppressive treatment beyond GC in all stages of EGPA patients out of the Northern German vasculitis centre cohort (Moosig et al. 2013); in detail, with an initial FFS (score) of one or higher, the intravenous bolus application of cyclophosphamide has been documented as the most frequent treatment regime (71\%).

In synopsis with the two cases we have presented here, there appears to be a rationale for an intensified immunosuppressive treatment approach beyond GC within the first week after EGPA diagnosis with GI involvement; conventional therapies such as cyclophosphasmide or previously establishing biological treatment modalities such as B cell depletion needs to be considered to avoid life-threatening GI manifestations with the goal to improve the outcome.

\section{Competing interests}

The authors declare that they have no competing interests.

\section{Authors' contributions}

GA, MM, and VZ have observed the patients and have collected the clinical data. VZ have performed the endoscopic biopsies. RB performed the histologic analysis. GA, VZ, and MP have done the research through the previous literature concerning EGPA cases with complications. GA, MP, VZ wrote the manuscript. All authors read and approved the final manuscript.

\section{Author details}

${ }^{1}$ University Medical School of Saarland, Rheumatology and Oncology, Kirrberger Strasse 1, D-66421 Homburg, Saar, Germany. ${ }^{2}$ Department of Pathology, University Medical School of Saarland, Homburg, Saar, Germany. ${ }^{3}$ Department of Medicine II Gastroenterology, University Medical School of Saarland, Homburg, Saar, Germany.

Received: 25 February 2014 Accepted: 6 June 2014

Published: 4 August 2014 


\section{References}

Bourgarit A, Le Toumelin P, Pagnoux C, Cohen P, Mahr A, Le Guern V, Mouthon L, Guillevin L, French Vasculitis Study Group (2005) Deaths occurring during the first year after treatment onset for polyarteritis nodosa, microscopic polyangiitis, and Churg-Strauss syndrome: a retrospective analysis of causes and factors predictive of mortality based on 595 patients. Medicine (Baltimore) 84(5):323-330

Çileda» A, Deniz H, Eleda» S, Özkal C, Düzgün N, Erekul S, Karnak D (2012) An aggressive and lethal course of Churg-Strauss syndrome with alveolar hemorrhage, intestinal perforation, cardiac failure and peripheral neuropathy. Rheumatol Int 32(2):451-455

Guillevin L, Lhote F, Gayraud M, Cohen P, Jarrousse B, Lortholary O, Thibult N, Casassus P (1996) Prognostic factors in polyarteritis nodosa and Churg-Strauss syndrome: a prospective study in 342 patients. Medicine (Baltimore) 75(1):17-28

Guillevin L, Cohen P, Gayraud M, Lhote F, Jarrousse B, Casassus P (1999) Churg-Strauss syndrome. Clinical study and long-term follow-up of 96 patients. Medicine (Baltimore) 78(1):26-37

Guillevin L, Pagnoux C, Seror R, Mahr A, Mouthon L, Le Toumelin P, French Vasculitis Study Group (FVSG) (2011) The Five-Factor Score revisited: assessment of prognoses of systemic necrotizing vasculitides based on the French Vasculitis Study Group (FVSG) cohort. Medicine (Baltimore) 90(1):19-27

Hayami C, Ishiguro N, Fukuya Y, Tokura Y, Kawashima M (2012) Churg-Strauss syndrome presenting with severe cutaneous and intestinal ulcers. Eur J Dermatol 22(3):397-399

Jennette JC, Falk RJ, Bacon PA, Basu N, Cid MC, Ferrario F, Flores-Suarez LF, Gross WL, Guillevin L, Hagen EC, Hoffman GS, Jayne DR, Kallenberg CG, Lamprecht P, Langford CA, Luqmani RA, Mahr AD, Matteson EL, Merkel PA, Ozen S, Pusey CD, Rasmussen N, Rees AJ, Scott DG, Specks U, Stone JH, Takahashi K, Watts RA (2013) 2012 revised International Chapel Hill Consensus Conference Nomenclature of Vasculitides. Arthritis Rheum 65(1):1-11

Moosig F, Bremer JP, Hellmich B, Holle JU, Holl-Ulrich K, Laudien M, Matthis C, Metzler C, Nölle B, Richardt G, Gross WL (2013) A vasculitis centre based management strategy leads to improved outcome in eosinophilic granulomatosis and polyangiitis (Churg-Strauss, EGPA): monocentric experiences in 150 patients. Ann Rheum Dis 72(6):1011-1017

Murakami S, Misumi M, Sakata H, Hirayama R, Kubojima Y, Nomura K, Ban S (2004) Churg-Strauss syndrome manifesting as perforation of the small intestine: report of a case. Surg Today 34(9):788-792

Nakamura Y, Sakurai Y, Matsubara T, Nagai T, Fukaya S, Imazu H, Hasegawa S, Ochiai M, Funabiki T, Mizoguchi Y, Kuroda M (2002) Multiple perforated ulcers of the small intestine associated with allergic granulomatous angiitis: report of a case. Surg Today 32(6):541-546

Pagnoux C, Guilpain P, Guillevin L (2007) Churg-Strauss syndrome. Curr Opin Rheumatol 19(1):25-32

Singh R, Singh D, Abdou N (2009) Churg-Strauss syndrome presenting as acute abdomen: are gastrointestinal manifestations an indicator of poor prognosis? Int J Rheum Dis 12(2):161-165

Vaglio A, Moosig F, Zwerina J (2012) Churg-Strauss syndrome: update on pathophysiology and treatment. Curr Opin Rheumatol 24(1):24-30

Varbanova M, Schütte K, Kuester D, Bellutti M, Franke I, Steinbach J, Scheidbach $H$, Malfertheiner $P(2011)$ Acute abdomen in a patient with ANCA-associated vasculitis. Dtsch Med Wochenschr 136(36):1783-1787

Venditti D, Valerio B, lelpo B, Buonomo O, Petrella G (2011) Bowel perforations in a patient affected by Churg-Strauss syndrome under high-dose steroid treatment: will alternative drugs reduce risk of surgery? Rheumatol Int 31(9):1239-1241

doi:10.1186/2193-1801-3-404

Cite this article as: Assmann et al:: Gastrointestinal perforation due to vasculitis at primary diagnosis of eosinophilic granulomatosis with polyangiitis (EGPA) despite a high dose glucocorticosteroids treatment. SpringerPlus 2014 3:404.

\section{Submit your manuscript to a SpringerOpen ${ }^{\circ}$ journal and benefit from:}

- Convenient online submission

- Rigorous peer review

- Immediate publication on acceptance

- Open access: articles freely available online

- High visibility within the field

- Retaining the copyright to your article

Submit your next manuscript at $\gg$ springeropen.com 